\title{
Heterogeneity of Age-Related Neural Hyperactivity along the CA3 Transverse Axis
}

\author{
${ }^{\circledR}$ Heekyung Lee, ${ }^{1}$ Zitong Wang, ${ }^{2}$ Scott L. Zeger, ${ }^{2}{ }^{\circledR}$ Michela Gallagher, ${ }^{3,4}$ and ${ }^{\circledR}$ James J. Knierim ${ }^{1,3,4}$ \\ ${ }^{1}$ Krieger Mind/Brain Institute, Johns Hopkins University, Baltimore, Maryland 21218, ${ }^{2}$ Department of Biostatistics, Johns Hopkins Bloomberg \\ School of Public Health, Baltimore, Maryland 21205, ${ }^{3}$ Department of Psychological and Brain Sciences, Johns Hopkins University, Baltimore, \\ Maryland 21218, and ${ }^{4}$ Solomon H. Snyder Department of Neuroscience, Kavli Neuroscience Discovery Institute, Johns Hopkins School of Medicine, \\ Baltimore, Maryland 21205
}

Age-related memory deficits are correlated with neural hyperactivity in the CA3 region of the hippocampus. Abnormal CA3 hyperactivity in aged rats has been proposed to contribute to an imbalance between pattern separation and pattern completion, resulting in overly rigid representations. Recent evidence of functional heterogeneity along the CA3 transverse axis suggests that proximal CA3 supports pattern separation while distal CA3 supports pattern completion. It is not known whether age-related CA3 hyperactivity is uniformly represented along the CA3 transverse axis. We examined the firing rates of CA3 neurons from young and aged, male, Long-Evans rats along the CA3 transverse axis. Consistent with prior studies, young CA3 cells showed an increasing gradient in mean firing rate from proximal to distal CA3. However, aged CA3 cells showed an opposite, decreasing trend, in that CA3 cells in aged rats were hyperactive in proximal CA3, but possibly hypoactive in distal CA3, compared with young $(\mathrm{Y})$ rats. We suggest that, in combination with altered inputs from the entorhinal cortex and dentate gyrus (DG), the proximal CA3 region of aged rats may switch from its normal function that reflects the pattern separation output of the DG and instead performs a computation that reflects an abnormal bias toward pattern completion. In parallel, distal CA3 of aged rats may create weaker attractor basins that promote abnormal, bistable representations under certain conditions.

Key words: aging; CA3; hippocampus; hyperactivity; pattern completion; pattern separation

Significance Statement

Prior work suggested that age-related CA3 hyperactivity enhances pattern completion, resulting in rigid representations. Implicit in prior studies is the notion that hyperactivity is present throughout a functionally homogeneous CA3 network. However, more recent work has demonstrated functional heterogeneity along the CA3 transverse axis, in that proximal CA3 is involved in pattern separation and distal CA3 is involved in pattern completion. Here, we show that age-related hyperactivity is present only in proximal CA3, with potential hypoactivity in distal CA3. This result provides new insight in the role of CA3 in age-related memory impairments, suggesting that the rigid representations in aging result primarily from dysfunction of computational circuits involving the dentate gyrus (DG) and proximal CA3.

Received Sep. 14, 2020; revised Nov. 12, 2020; accepted Nov. 19, 2020.

Author contributions: H.L. and J.J.K. designed research; H.L. performed research; H.L., Z.W., and S.L.Z. analyzed data; H.L. wrote the first draft of the paper; Z.W., S.L.Z., M.G., H.L. and J.J.K. wrote the paper.

This work was supported by the Public Health Service Grant P01 AG009973 from the National Institute of Aging. We thank Robert McMahan, Andrew Sherwood, Nicholas Lukish, Arjuna Tillekeratne, and Kimberly Nnah for assistance in running the behavior experiments and histological procedures.

M.G. is the founder of AgeneBio Incorporated, a biotechnology company that is dedicated to discovery and development of therapies to treat cognitive impairment, and has a financial interest in the company and is an inventor on Johns Hopkins University's intellectual property that is licensed to AgeneBio. Otherwise, M.G. has had no consulting relationships with other public or private entities in the past three years and has no other financial holdings that could be perceived as constituting a potential conflict of interest. All conflicts of interest Are managed by Johns Hopkins University. All other authors declare no competing financial interests.

Correspondence should be addressed to Heekyung Lee at heekyung@jhu.edu or James J. Knierim at jknierim@jhu.edu.

https://doi.org/10.1523/JNEUROSCI.2405-20.2020

Copyright $(2021$ the authors

\section{Introduction}

Elevated excitability in some regions of the hippocampus contributes to impaired memory function in aging (Yassa and Stark, 2011; Samson and Barnes, 2013; Haberman et al., 2017a; Gray and Barnes, 2019). Specifically, heightened activation localized to the dentate gyrus (DG)/CA3 regions of the hippocampus is correlated with memory deficits in aging and in prodromal Alzheimer's disease (AD), such as in patients with amnestic mild cognitive impairment (aMCI; Yassa et al., 2010, 2011; Bakker et al., 2012, 2015; Reagh et al., 2018). In agreement with those data, augmented neural activity occurs in the CA3 region in aged rats (Wilson et al., 2005; Robitsek et al., 2015; Haberman et al., 2017b; Maurer et al., 2017) and in aged primates (Thomé et al., 2016). Treatments to reduce hyperactivity with low-dose administration of the atypical antiepileptic levetiracetam reduced firing rates and IEG markers of hyperactive CA3 neurons (Robitsek et 
al., 2015; Haberman et al., 2017b) and improved performance on memory tasks in aged rats (Koh et al., 2010; Haberman et al., 2017a). Therapeutic efficacy with levetiracetam treatment has also been demonstrated in aMCI patients, who showed reductions in task-related DG/CA3 hippocampal activation and improved memory performance (Bakker et al., 2012, 2015).

Hippocampal place cells fire in specific locations when an animal explores an environment (O'Keefe and Dostrovsky, 1971; O'Keefe, 1976). CA3 place cells in aged rats have been described as "rigid," in that they maintain the same spatial representation abnormally across familiar and novel environments (Wilson et al., 2005; Robitsek et al., 2015). Abnormal DG/CA3 activity in old age has also been linked to a reduced ability to discriminate between similar objects in both humans (Yassa et al., 2010, 2011; Bakker et al., 2012, 2015; Reagh et al., 2018; Berron et al., 2019) and in aged rats (Johnson et al., 2017; Maurer et al., 2017). CA3 hyperactivity is suggested to bias the aged CA3 toward pattern completion, promoting maintenance of stored representations rather than formation of new ones, resulting in rigidity of CA3 place fields (Wilson et al., 2006). However, age-related memory deficits are not only characterized by overly rigid representations. CA1 place cells in aged rats failed to stably retrieve the same map in a familiar environment (Barnes et al., 1997), suggesting that aged rats improperly remap in a familiar environment. Thus, the role of the hippocampus in the organization and representation of information may be compromised in aging, resulting in incorrect retrieval of the wrong maps for a given environment (Rapp, 1998; Redish et al., 1998; Tanila, 1998; Wilson et al., 2004).

Recent studies have shown compelling evidence for anatomic and functional heterogeneity along the CA3 transverse axis (Ishizuka et al., 1990; Witter, 2007; Hunsaker et al., 2008; Nakamura et al., 2013; Marrone et al., 2014; Lee et al., 2015; Lu et al., 2015; Sun et al., 2017). In comparison with each other, proximal CA3 $(\mathrm{CA} 3 \mathrm{c})$ receives greater input from the DG, whereas distal CA3 (CA3a) receives greater input from the entorhinal cortex and from the CA3 recurrent collateral systems (Witter, 2007; Sun et al., 2017). Functional gradients along the CA3 transverse axis suggest that proximal $\mathrm{CA} 3$, in conjunction with the DG, supports pattern separation and distal CA3, with its extensive, recurrent collateral system, supports pattern completion (Lee et al., 2015; Lu et al., 2015). Proximal and distal CA3 send topographically organized projections to distal and proximal CA1, respectively, to form functionally distinct, parallel processing streams along the transverse axis in the hippocampal circuit (Amaral and Witter, 1989; Ishizuka et al., 1995; Lee et al., 2020). To investigate how aged CA3 hyperactivity may affect the parallel processing circuits within the hippocampus, we examined the CA3 place cell firing rates of young $(\mathrm{Y})$ and aged rats. We show that the age-related CA3 firing rates are hyperactive in the proximal region but not in the distal region, where they may be hypoactive instead.

\section{Materials and Methods}

\section{Subjects and surgery}

A total of 18 male Long-Evans rats (four young; 14 aged) were used in this study. Male rats (retired breeders) were obtained at nine months of age from Charles River Laboratories and individually housed with ad libitum access to food and water during a 12/12 h light/dark cycle in a vivarium at Johns Hopkins University until 22-26 months of age, at which time behavioral assessment in the water maze was performed. Y rats were obtained from the same source and were housed in the same vivarium and tested at four to six months of age. After the behavioral assessment, all rats underwent hyperdrive implant surgery, and were housed during a reversed 12/12 h light/dark cycle. All recordings were done during the dark cycle. All animal care, housing, and surgical procedures conformed to the National Institutes of Health standards using protocols approved by the Institutional Animal Care and Use Committee at Johns Hopkins University.

All rats were prescreened for spatial learning ability in the Morris water maze as previously described (Gallagher et al., 1993; Branch et al., 2019) before the implantation of recording electrodes. Briefly, all rats were trained for $8 \mathrm{~d}$ (three trials per day) in the water maze to locate a submerged escape platform that remained at the same location in the tank. Every sixth trial was a probe trial (no escape platform for the first $30 \mathrm{~s}$ ), allowing assessment of search proximity. The learning index (LI), an average of weighted proximity scores obtained during probe trials (Gallagher et al., 1993), was used to classify animals as aged-impaired (AI) or aged-unimpaired (AU), with low scores reflecting a more accurate search. An a priori LI cutoff at 240 was used to segregate aged rats into unimpaired ( $\mathrm{LI}<240$, similar to $\mathrm{Y}$ rats) and impaired ( $\mathrm{LI}>240$; Gallagher et al., 1993; Branch et al., 2019). On day 9, all rats were given six trials to locate a visible platform above the water level to screen for nonspecific task impairment such as swimming behavior and escape motivation. Following water maze testing, all rats were placed on restricted food access to reduce their body weight to $85 \%$ while they were given foraging sessions $(20 \mathrm{~min} / \mathrm{d}$ for $10 \mathrm{~d}$ ) in a cylindrical apparatus. These foraging sessions were given to accustom the rats to forage for chocolate pellets (Bio-Serv) before the subsequent training on the circular track.

For hyperdrive implantation, a custom-built recording drive that contained 15 independently moveable tetrodes was surgically implanted over the right hemisphere. To optimize the drive placement, recordings were performed during the surgery to find the lateral edge of $\mathrm{CA} 3$, which served as a landmark for the mediolateral placement of the drive; the most lateral tetrode ranged from 3.7 to $4.2 \mathrm{~mm}$ lateral to bregma and 3.4 to $4.0 \mathrm{~mm}$ posterior to bregma. The tetrode array was configured as an oval bundle, $\sim 1.2 \mathrm{~mm}$ in length and $0.9 \mathrm{~mm}$ in width, and encompassed a $3 \times 6$ array of tetrodes spaced $\sim 300 \mu \mathrm{m}$ apart. The array was implanted at an angle of $\sim 35^{\circ}$, which is approximately parallel to the transverse axis of the dorsal hippocampus.

\section{Behavior apparatus}

Over the course of two to three weeks, the rats' weights were reduced to $80-85 \%$ of free-feeding weights for the Y rats and $75 \%$ for aged rats. All rats were trained to run clockwise on the circular track for chocolate pellets. The circular track with salient local texture cues was placed in a black curtained room with salient global cues. Experiments were conducted for $4 \mathrm{~d}$, with five sessions each day. Three standard sessions (local and global cue relationships remained constant) were interleaved with two mismatch sessions (local and global cues were rotated by equal increments but in opposite directions; Knierim, 2002). For this report, we analyzed cells only from the standard sessions to rule out any influence that may result from cue manipulations in the mismatch sessions. The three standard sessions are referred to as session 1 , session 2 , and session 3 in the main text.

\section{Electrophysiological recordings}

Tetrodes were made from $17 \mu \mathrm{m}$ platinum-iridium wires (California Fine Wire Co). Impedance of the platinum wires was reduced to $\sim 120 \mathrm{k} \Omega$ by electroplating them with platinum black. Neural signals were recorded using a 64-channel wireless transmitter system (Triangle Biosystems International) and transmitted to a Cheetah Data Acquisition System (Neuralynx). The signals were amplified 1000-5000 times and filtered between $600 \mathrm{~Hz}$ and $6 \mathrm{kHz}$ (for units) or 1 and $600 \mathrm{~Hz}$ (for local field potential (LFP)). The spike waveforms above a threshold of $40-70 \mu \mathrm{V}$ were sampled for $1 \mathrm{~ms}$ at $32 \mathrm{kHz}$, and LFPs were continuously sampled at $32 \mathrm{kHz}$. The rat's position was tracked with an overhead camera recording light emitting diodes (LEDs) positioned over the head of the rat (red LEDs in front and green LEDs behind) at $30 \mathrm{~Hz}$.

\section{Data analysis}

Unit isolation

Multiple waveform characteristics (e.g., spike amplitude and energy) were used to isolate single units using custom-written, manual cluster- 
cutting software. Cells were assigned to subjective isolation quality scores from 1 (very good) to 5 (poor), depending on the distance each cluster was separated from the other clusters and from the background activity level. Cluster isolation was judged independent of the behavioral firing correlates of the cells. Three parameters were used to classify cell types: spike width, mean firing rate, and burst index. Using a K-means clustering analysis on these parameters, cells were classified as putative pyramidal cells (low-rate, broad spikes, bursty) or putative interneurons (high-rate, narrow spikes, nonbursty) for each session. If a cell was classified as a putative interneuron (i.e., a high rate cell) in one of the sessions, that cell was classified as an interneuron for all sessions. Only well-isolated putative pyramidal cells (with isolation quality scores 1-3) were included in the analysis. Putative interneurons were excluded from the analysis.

Rate maps and place fields

The position and the head direction of the rat were based on tracking the LEDs on the headstage connected to the hyperdrive. Analysis was performed on data restricted to times when the animal's head was within the boundaries of the circular track and the animal was moving forward on the track at a speed $>3 \mathrm{~cm} / \mathrm{s}$. The $x$ and $y$ dimensions of the camera image $(640 \times 480$ pixels $)$ were divided into bin sizes of 10 pixels. A $2 \mathrm{D}$ firing rate map of a cell was generated by dividing the number of spikes of a single neuron in each bin by the amount of time the rat spent in that bin. For quantitative analysis, $2 \mathrm{D}$ rate maps were transformed into linear rate maps by converting the rat's Cartesian position into units of degrees on the circular track. Linearized rate maps were divided into 360 bins $\left(1^{\circ} /\right.$ bin $)$ and smoothed with a Gaussian filter $\left(\sigma=3^{\circ}\right)$ and were used to calculate the spatial information score (Skaggs et al., 1996), the mean and the peak rates, and the place field size. Place cells were identified as neurons with spatial information scores $>0.75$ bits/ spike, spatial information significance $p<0.01$, and number of ontrack running spikes $>50$. Spatial information significance was calculated with a shuffling procedure, in which the spike train and the position train were shifted relative to each other by a random time (minimum $30 \mathrm{~s}$; the later time stamps at the end of the session were wrapped around to the beginning of the session), the rate map was recalculated, and a spatial information score was calculated. This procedure was performed 1000 times, and the cell was considered significant at $p<0.01$ if the true information score exceeded the values of $>990$ scores from the shuffling procedure. Place field boundaries were determined using a floor threshold set to $10 \%$ of the peak firing rate. Bins with firing rates greater than the floor threshold were tracked in each direction from the peak bin of the place field until four consecutive subthreshold bins were reached. The size of each place field was measured across those above-threshold bins. The peak firing rate was the maximum firing rate in the rate map, and the mean firing rate was calculated by dividing the number of running spikes by the duration of the session.

\section{Rotational analysis}

The linearized rate map in the first standard session (session 1) was correlated with the linearized rate map in the third standard session (session 3 ). The linearized rate map in session 3 was then circularly shifted in $1^{\circ}$ increments and was correlated with the session 1 rate map at each increment. The shift producing the maximum correlation was assigned as that place field's rotation angle.

\section{Histologic procedures}

Rats were deeply anesthetized and perfused with $4 \%$ formaldehyde. Frozen coronal sections $(40 \mu \mathrm{m})$ were cut and stained with cresyl violet. Images of the brain slices were acquired with an IC Capture DFK 41BU02 camera (The Imaging Source) attached to a Motic SMZ-168 stereoscope. All tetrode tracks were identified, and the lowest point of the track was used to determine the recording location. The position of the tetrode along the CA3 transverse axis was normalized from 0 to 1 , with the distal end as 1 . Distance of the CA3 tetrode was measured manually from the proximal end and scaled by the total length of CA3.

\section{Statistical analysis}

Statistical tests were calculated using MATLAB (MathWorks) and R (R Core Team, 2013). For group comparisons, data were first log- transformed because of the highly skewed distributions of the raw data (although the original data are presented in figures). Two-way ANOVAs with post hoc Tukey's tests were then performed and considered significant at $p<0.05$.

\section{Linear mixed effects models}

Linear mixed effects regression models were used to estimate (separately for the $\mathrm{Y}, \mathrm{AU}$, and $\mathrm{AI}$ animals) the mean firing rate as a function of the neuron's distance along the CA3 transverse axis, with and without control for animal running speed. The response variable was the total spike count for a cell divided by its total number of frames. The key predictors were the age group of the animal and the location of the neuron along the transverse axis. To compare the mean rate of firing among the three groups of rats, a linear mixed effects model was used after log transforming the observed rates. The fixed effects in the model included two indicator variables for the three groups interacting with a smooth function of location (natural cubic spline with 2 df; Hastie et al., 2009). The random effects allow animals to have random intercepts and random linear slopes along the CA3 axis; the random effects account for correlation among cells from the same animal so that the inferences about the group differences are valid.

We used a Wald test of the null hypothesis that the three groups shared the same firing rate curve as a function of location (Aitchison and Silvey, 1960). The Wald test statistic was compared with a $\chi^{2}$ distribution with $4 \mathrm{df}$ (number of groups - 1=2) $\times$ (number of degrees of freedom for each curve $=2$ ). We also calculated $95 \%$ confidence intervals (CIs) for the predicted curves for each group that are linear contrasts of the regression coefficients. To control for confounding by running speed, each animal's speed was then included in the fixed effects as a natural cubic spline with $3 \mathrm{df}$. Otherwise the two analyses were the same.

\section{Results}

Multielectrode recordings were made from neurons along the dorsal CA3 transverse axis (Fig. $1 A$ ) from four $\mathrm{Y}$, seven $\mathrm{AU}$, and seven AI rats. Locations between $0 \%$ and $40 \%$ of the proximodistal length were defined as proximal CA3, $40-70 \%$ as intermediate CA3, and $70-100 \%$ as distal CA3 (Lu et al., 2015). The aged rats were pretested in the Morris water maze and categorized as learning impaired or learning unimpaired based on pre-determined LI scores (Gallagher et al., 1993; Branch et al., 2019; Fig. $1 B)$. All rats were then trained to run clockwise on a circular track containing salient local texture cues in a curtained room containing salient global landmark cues (Fig. 1C).

Using a K-means clustering analysis on three parameters (spike width, mean firing rate, burst index), cells were classified as putative pyramidal cells (low-rate, broad spikes, bursty) or putative interneurons (high-rate, narrow spikes, nonbursty) for each session (Fox and Ranck, 1975, 1981; Csicsvari et al., 1998, 1999). The total number of classified putative pyramidal cells and putative interneurons from each rat is shown in Table 1. Figure $1 D$ shows the classification for each cell-session (i.e., each cell can contribute up to three data points per day). There were few interneurons (red circles) recorded from Y rats, and they all showed the classic interneuron spatial firing pattern of being diffusely active at high rates along the entire track (Fox and Ranck, 1975, 1981; Csicsvari et al., 1998, 1999). In aged groups, some of the cells in the putative interneuron cluster did not seem like typical interneurons. Some fired at high rates but had broad spike waveforms more commonly associated with pyramidal cells (AU cell 3; AI cell 3). Such cells have been reported previously in CA1 from young adult rats (Csicsvari et al., 1999), and the lack of these cells in Y rats in the present data set likely is the result of the limited data set. However, some of the putative interneurons from aged rats had unusual spatial firing patterns. Whereas a 


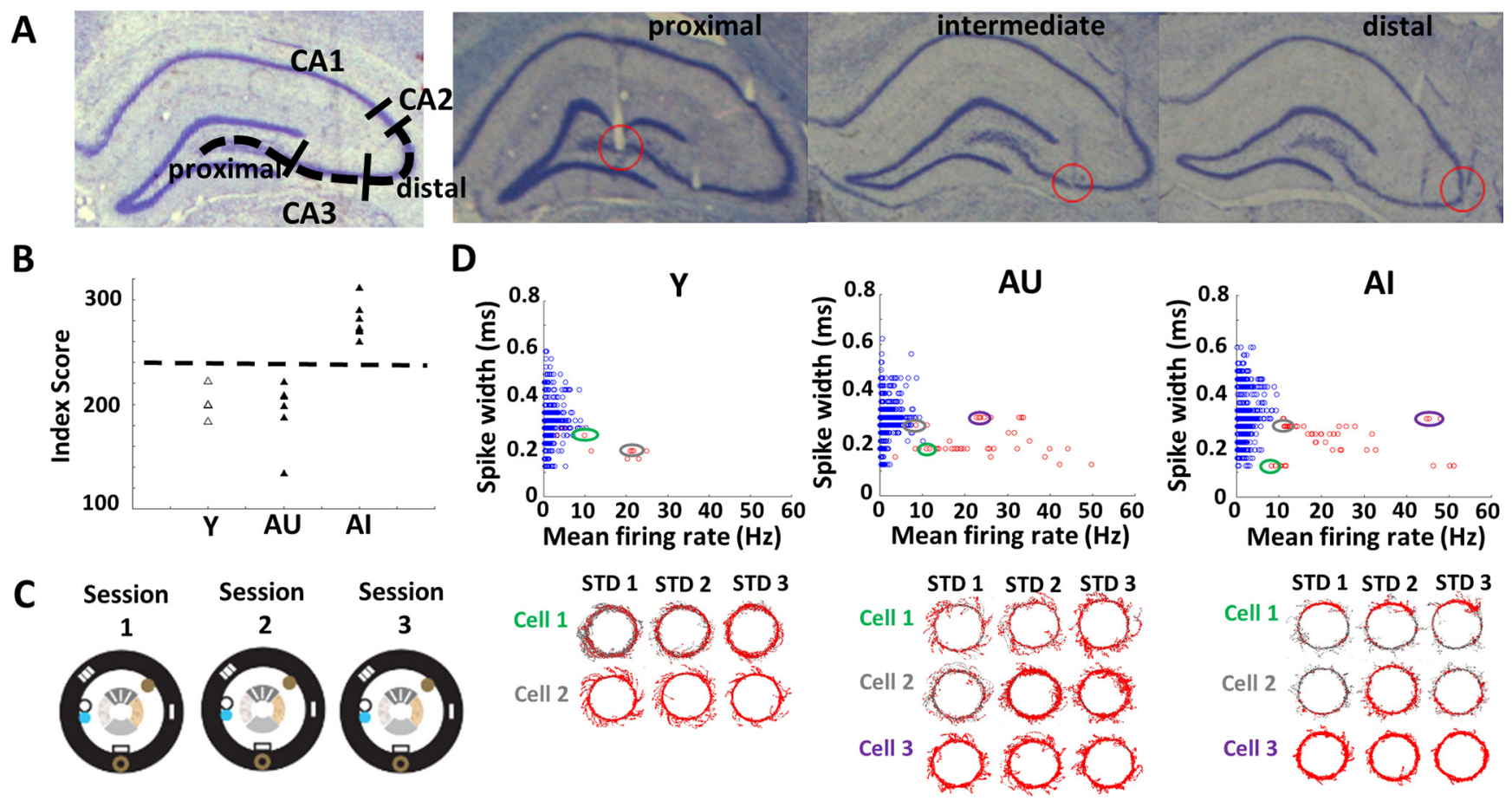

Figure 1. CA3 recording locations and cell classifications. $A$, Recordings were made along the CA3 transverse axis. Locations between $0 \%$ and $40 \%$ of the axis length were defined as proximal, $40 \%$ and $70 \%$ as intermediate, and $70 \%$ and $100 \%$ as distal CA3 (left). Nissl-stained brain sections showing representative tetrode tracks in proximal, intermediate, and distal CA3 subregions (right). B, A LI score for each rat was derived during the probe trials during the water maze training, with lower scores indicating more accurate performance. Aged rats that performed on par with $\mathrm{Y}$ rats were designated as $\mathrm{AU}$, and those that performed more poorly than $\mathrm{Y}$ rats (index score $>240$ ) were designated as Al. C, Recordings were made during three sessions, in which the local and global cues were in a fixed configuration that the rat had experienced in all preceding training trials. $\boldsymbol{D}$, Classification of putative pyramidal cells and putative interneurons were made using three parameters: spike width, mean firing rate, and burst index. Using a K-means clustering analysis, blue circles represent cells classified as putative pyramidal cells and red circles represent cells classified as putative interneurons. Each circle is a cell recorded in one session. Hence, a cell can contribute up to three data points a day. Some of the classified putative interneurons had unusual firing patterns. Some cells in AU and Al rats had marked changes in their firing rates across sessions (AU cell 2; Al cell 2); one cell in the Al group had a very strong place field on the track (Al cell 1).

Table 1. Total number of classified putative pyramidal cells and putative interneurons from each rat

\begin{tabular}{|c|c|c|c|c|c|c|c|c|}
\hline \multicolumn{3}{|l|}{ Y } & \multicolumn{3}{|l|}{$\mathrm{AU}$} & \multicolumn{3}{|l|}{ Al } \\
\hline Rat \# & Putative pyramidal & Putative interneuron & Rat \# & Putative pyramidal & Putative interneuron & Rat \# & Putative pyramidal & Putative interneuron \\
\hline 160281 & 37 & 2 & 151055 & 48 & 7 & 151170 & 42 & 0 \\
\hline 180576 & 110 & 2 & 161152 & 52 & 1 & 170869 & 25 & 0 \\
\hline \multirow[t]{2}{*}{180685} & 92 & 0 & 170654 & 61 & 0 & 180730 & 40 & 5 \\
\hline & & & 170711 & 31 & 1 & 180821 & 47 & 1 \\
\hline
\end{tabular}

Cells are not independent observations as data were taken across $4 \mathrm{~d}$ of recordings and no attempt was made to identify and track the same cell across the $4 \mathrm{~d}$.

typical interneuron will fire at similar rates in all sessions (but see Wilent and Nitz, 2007), some of the cells in AU and AI rats had marked changes in their firing rates across sessions (AU cell 2; AI cell 2). One cell in the AI group was classified as a putative interneuron because of its high firing rate and narrow spike, yet it had a very strong place field on the track (AI cell 1). Because of the limited sampling of these cells, no quantitative analyses have been performed and they are presented for descriptive purposes only. If a cell was classified as a putative interneuron (i.e., a high rate cell) in one of the sessions, that cell was classified as a putative interneuron for all sessions and excluded from further analysis, leaving only well-isolated, putative pyramidal cells (blue circles) in the analyses. Since the same cell can be counted up to three times (i.e., three sessions) in a given recording day, the values across all sessions in which a cell was active were averaged so that each cell contributed only one value to the analysis that day.

Most CA3 pyramidal cells are silent, or fire only rarely, in a given environment (Ahmed and Mehta, 2009; Alme et al., 2014), so we focused analysis on active pyramidal cells. A well-isolated pyramidal cell was considered active if the cell fired $>50$ spikes while the rat was moving $>3 \mathrm{~cm} / \mathrm{s}$ in a given session. An active cell was considered a place cell if it had a spatial information score $>0.75$ bits/spike at a significance level $p<0.01$ (Skaggs et al., 1996) and $>50$ spikes when the rat's head was on the track (i.e., excluding head-scanning epochs when the rat's forward movement was paused but its head was off the track; Monaco et al., 2014). As expected (Barnes et al., 1983, 1997; Shen et al., 1997; Tanila et al., 1997a,b; Wilson et al., 2005; Robitsek et al., 2015), place cells were observed in all age groups across the three 
A

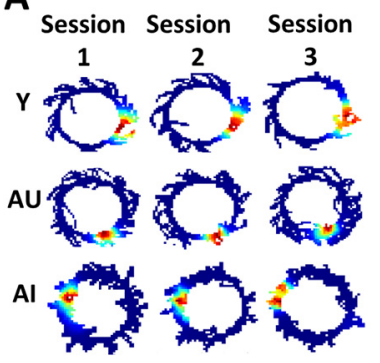

B

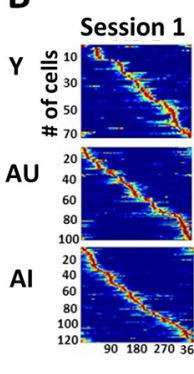

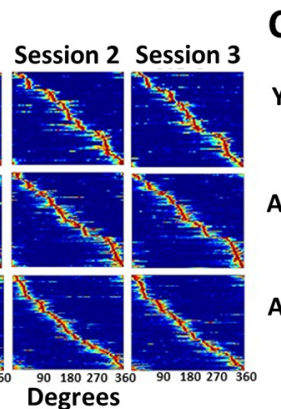

$\mathbf{E}$
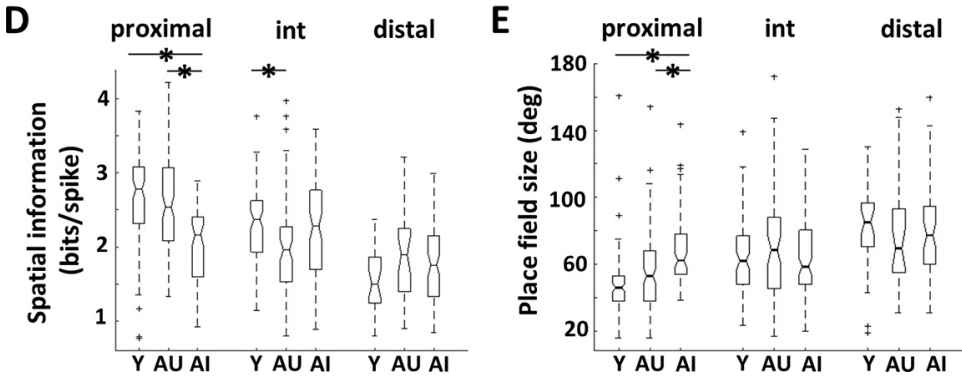

Figure 2. Place field properties in $Y, A U$, and $A I$ rats. $A$, Example cells recorded in all three sessions from $Y, A U, A I$ rats. $B$, From all four recording days, place cells that passed the inclusion criteria in all three sessions were ordered by the peak positions of their linearized rate maps in the first session (session 1). The positions of place fields that were active in all three sessions remained stable in all age groups. Firing rates of each place cell were normalized across the three sessions. The blue color indicates the minimum normalized firing rate (0), and the red color indicates the maximum firing rate (1). C, The rotation amounts of the place fields between the first session (session 1) and the last session (session 3) were calculated. Comparisons of the rotation amounts did not show a significant difference across the age groups. Spatial information scores $(\boldsymbol{D})$ and place field sizes $(\boldsymbol{E})$ both showed significant group $\times$ region interaction effects. Both $Y$ and $A U$ rats showed decreasing spatial information scores from proximal to distal CA3 with corresponding increasing place field sizes from proximal to distal CA3. In Al rats, the spatial information scores and the place field sizes failed to show a normal gradient along the CA3 transverse axis. Post hoc Tukey's tests $(* p<0.05)$ showed a significant group difference in the proximal region, with Al rats showing lower spatial information scores and larger place field sizes compared with $\mathrm{Y}$ and $\mathrm{AU}$ rats.

sessions (Fig. 2A). To examine place cell spatial stability, we analyzed a subset of cells that met place-cell criteria in all three sessions. Place cells were ordered by the peak position of their linearized rate maps in the first session (session 1). Place field ordering remained stable in all three sessions in all age groups (Fig. 2B). To quantify the stability, we calculated the angular difference in the location of each place field on the circular track between sessions 1 and 3. For all three age groups, the angular difference was centered around $0^{\circ}$ with no significant age difference (Kruskal-Wallis test; $\chi^{2}[2]=0.55, p=0.76$; Fig. $2 C$ ).

Although place fields were stable in all groups, there were significant age differences in their spatial properties. Spatial information scores (two-way ANOVA: group: $F_{(2,615)}=6.26, p=$ 0.002; region: $F_{(2,615)}=38.9, p<0.0001$; and interaction: $F_{(4,615)}=$ 7.36, $p<0.0001$; Fig. $2 D$ ) and place field sizes (two-way ANOVA: group: $F_{(2,615)}=2.87, p=0.057$; region: $F_{(2,615)}=30.71, p<0.0001$; and interaction: $F_{(4,615)}=6.08, p<0.0001$; Fig. $\left.2 E\right)$ both showed significant group $\times$ region interaction effects. In $\mathrm{Y}$ and $\mathrm{AU}$ rats, the spatial information scores showed a decreasing trend from proximal to distal CA3, and correspondingly, the place field sizes showed an increasing trend from proximal to distal CA3. These results are consistent with previous studies showing a decrease in spatial tuning from proximal to distal along the CA3 transverse axis in Y rats (Lee et al., 2015; Lu et al., 2015). In contrast, the spatial information scores and the place field sizes of AI rats remained similar across the subregions. Post hoc Tukey's tests $(p<0.05)$

showed a significant difference in the proximal region with AI rats showing lower spatial information scores with larger place field sizes compared with $\mathrm{Y}$ and $\mathrm{AU}$ rats, but no differences in distal CA3. These data suggest that AI rats do not show a normal gradient in spatial selectivity along the transverse axis, because of abnormally low spatial information in proximal CA3 but normal spatial selectivity in distal CA3.

Aged CA3 place cells are hyperactive in proximal CA3 but possibly hypoactive in distal CA3

Young and aged CA3 place cells showed a gradient in mean firing rate along the CA3 transverse axis, but the gradients trended in opposite directions. While the young CA3 cells showed an increasing gradient in the mean firing rates from proximal to distal CA3 (as previously reported by Lee et al., 2015; Lu et al., 2015), aged CA3 cells showed a decreasing gradient from proximal to distal CA3. Aged CA3 cells in the proximal region were hyperactive in both $\mathrm{AI}$ and $\mathrm{AU}$ rats but hypoactive in distal CA3 compared with $Y$ rats (two-way ANOVA: group: $F_{(2,615)}=0.83, p=0.44$; region: $F_{(2,615)}=1.96$, $p=0.14$; and interaction: $F_{(4,615)}=5.22 p=0.0004$; Tukey's post hoc tests, $p<0.05$; Fig. $3 A$ ).

The data presented in Figure $3 A$ were analyzed using standard methods from single-unit neurophysiology that typically treat each cell as an independent sample. However, certain assumptions of classic parametric statistical hypothesis-testing may be violated by these methods. (1) There may be correlations among the cells within an animal that violate the assumption of independence of each data point. (2) Data were taken across $4 \mathrm{~d}$ of recordings, and a typical level of instability of extracellular recordings makes it unknown which cells, and how many cells, were recorded more than once across the $4 \mathrm{~d}$. Thus, the statistical power of these tests is artificially increased by an inflated sample size of unknown magnitude. (3) Inhomogeneities in sampling across animals (e.g., some animals may be biased toward proximal recording sites while others are biased toward distal sites) may also cause improper conclusions when the individual cells are pooled together. Because of these concerns, prior investigators have correctly argued that it is more conservative to use the individual animal as the unit of sampling for such statistical tests (Shen et al., 1997). However, such a conservative approach may reduce the power of the statistical tests, and it is often impractical to record from enough animals per group in these experiments, which require multiple months of effort per animal. Although preliminary analyses indicated that there was much greater variance among cells within an animal (93\% of all variance) compared with variability across animals ( $7 \%$ of all variance), it was still possible that inclusion of a few outlier animals in one age group might skew the results. We thus used a linear mixed effects model (Laird and Ware, 1982) to account for the correlations among cells within an animal and the variability across animals to supplement the classic ANOVA tests. This analysis also allowed us to analyze location along the transverse axis as a continuous variable, rather than a somewhat artificial classification into discrete subregions (proximal, intermediate, distal). 
Figure $3 B$ shows the firing rates of each cell (log-scale ordinate, averaged across the three sessions of the day, as in Fig. 2) for each tetrode location across all animals (abscissa). The lines show the model's best cubic-spline fits (see Materials and Methods). The average curves across animals differed significantly between the $\mathrm{Y}$ and AU groups $(p=0.03)$ and between the $\mathrm{Y}$ and AI groups $(p=0.01)$, but not between $\mathrm{AU}$ and $\mathrm{AI}$ groups $(p=0.61)$. Consistent with the ANOVA results, the $\mathrm{AI}$ and $\mathrm{AU}$ groups show a $19 \%$ hyperactivity in the more proximal region (location 0.01 in Fig. $3 B$ ), the curves crossover midway through the transverse axis in the intermediate region, and the $\mathrm{AI}$ and $\mathrm{AU}$ groups show a $46 \%$ reduction in firing rate in the more distal regions (location 0.91). Figure $3 C$ shows the data organized according to each animal, to show the variability in recording locations across subjects and the different relationships of firing rate to transverse axis location across animals that the linear mixed effects model takes into account.

\section{Speed does not account for the firing rate differences}

Place cell firing rates are correlated with the animal's running speeds (McNaughton et al., 1983; Wiener et al., 1989; Czurkó et al., 1999; Hirase et al., 1999; Ekstrom et al., 2001; Maurer et al., 2005). Because the aged rats ran at slower speeds on average compared with Y rats (Fig. 4A), speed can be a confounding variable that may contribute to the firing rate differences observed between the age groups. Thus, we ran another version of the same statistical model that incorporates momentary speed as a fixed effect that accounts for the potentially confounding effect of this variable. The results are similar to the model without the speed variable (Fig. 4B). The curves differ significantly between the $\mathrm{Y}$ and AU groups $(p=0.03)$ and between the $\mathrm{Y}$ and AI groups $(p=0.002)$, but not between AU and AI groups $(p=0.47)$. The hyperactivity of aged rats in proximal CA3 appears even stronger when speed is accounted for, compared with the previous model (Fig. 3B), with the AI and AU groups showing a $72 \%$ hyperactivity in the more proximal region (location 0.01 ) and a $25 \%$ reduction in the more distal regions (location 0.91) compared with Y group. However, the hypoactivity of aged rats in distal CA3 appears weaker, and the crossover point is further toward the distal end. Based on the a priori definition of 0.7 being the transition between intermediate and distal CA3 (Lu et al., 2015), we tested
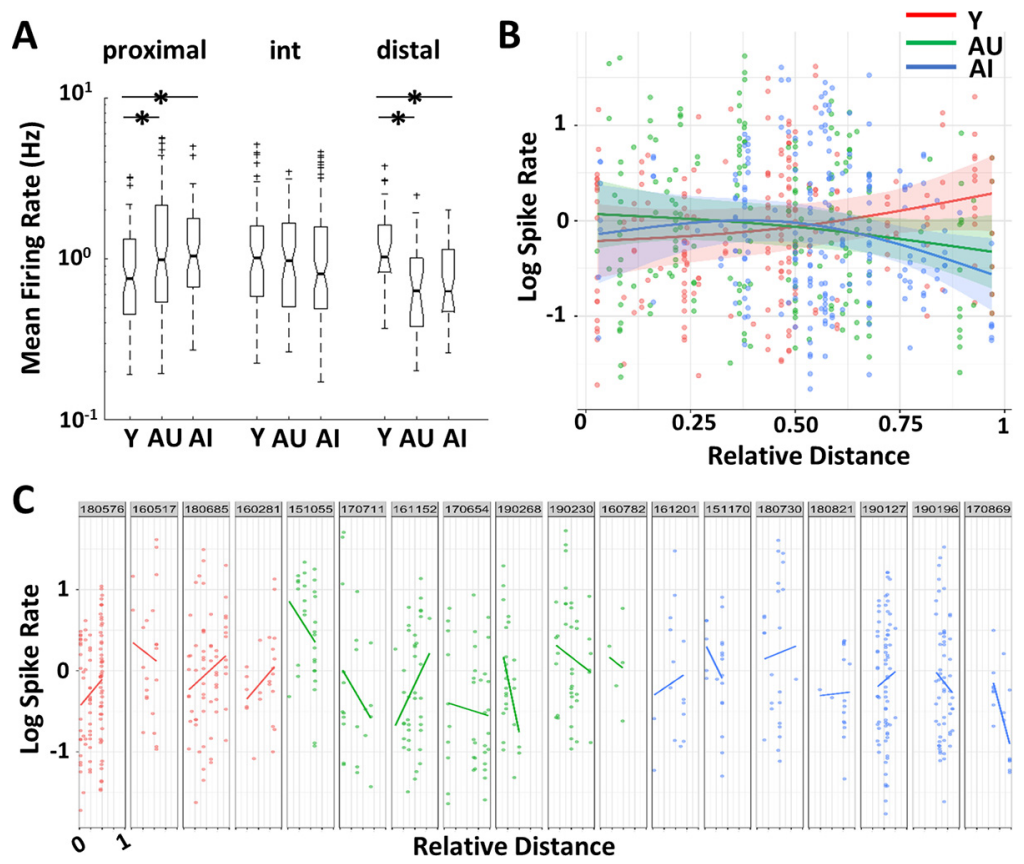

Figure 3. Age-related CA3 hyperactivity shows subregion differences along the transverse axis. $\boldsymbol{A}$, Mean firing rates of place cells showed a significant group $\times$ region interaction effect. Post hoc Tukey's tests $(* p<0.05)$ showed significant group differences in that aged CA3 cells were hyperactive in the proximal region but hypoactive in the distal region compared with young CA3 cells. $B, A$ linear mixed effects model was used to compare the mean firing rates along the transverse axis as a continuous variable, rather than a discrete subregion. Each circle (red $=Y$; green $=\mathrm{AU}$; blue $=\mathrm{Al}$ ) is a cell recorded at the location along the transverse axis. The solid lines show the model's best fits, with $95 \% \mathrm{Cls}$. Consistent with $\boldsymbol{A}$, both $\mathrm{AU}$ and Al show hyperactivity in the proximal region but hypoactivity in the distal region, compared with $Y$ rats. $C$, Data showing observed mean firing rates along the transverse axis organized according to each animal.
A

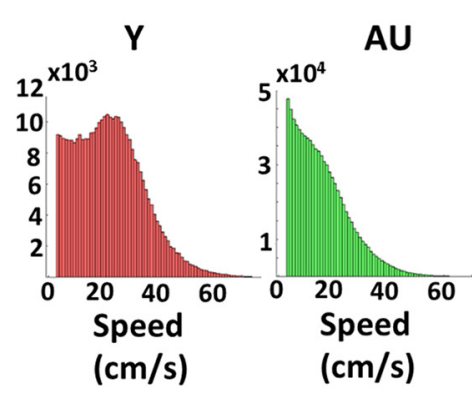

C

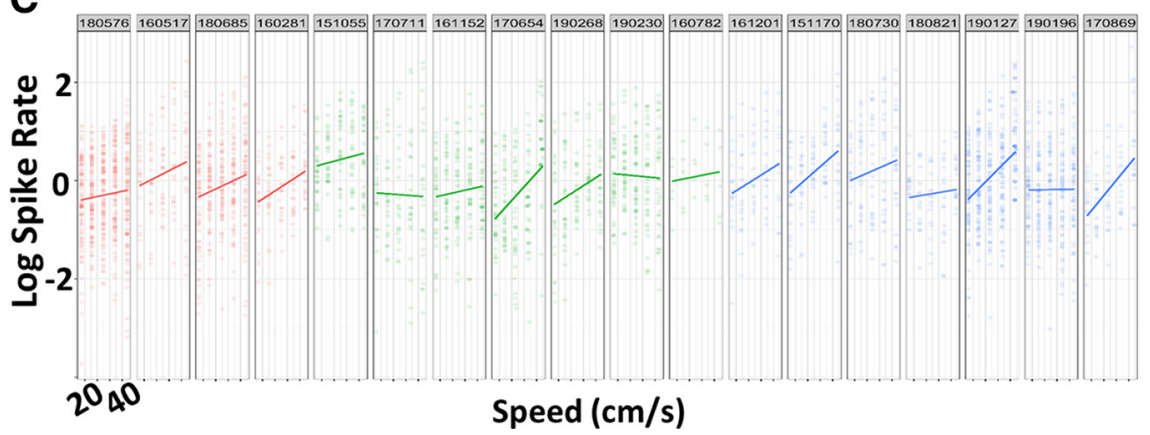

Figure 4. Speed does not account for the firing rate differences. $\boldsymbol{A}$, Histograms showing the distribution of speeds for each age group while animals were running on the circular track. Aged rats ran at slower speeds compared with $Y$ rats. $B, A$ linear mixed effects model that incorporates momentary speed as a fixed effect was used to analyze mean firing rate along the CA3 transverse axis. The solid lines show the model's best fits, with $95 \%$ Cls. With the confounding influence of speed taken into account, both AU and Al still showed hyperactivity in proximal CA3 but potential hypoactivity in distal CA3. C, Data showing the observed mean firing rate relationship with the rat's running speeds organized according to each animal. 
A Rat 151170

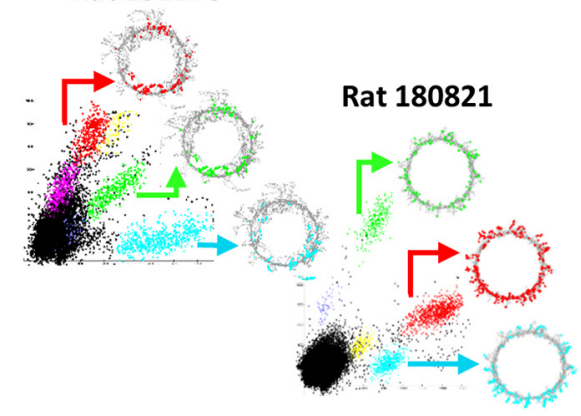

B

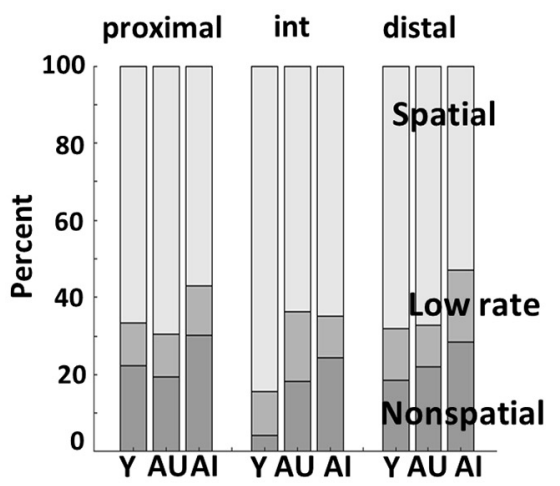

C

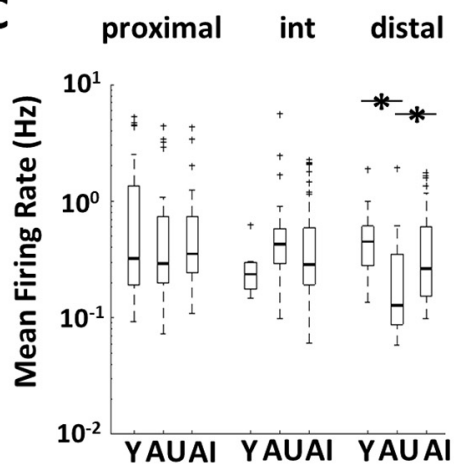

D

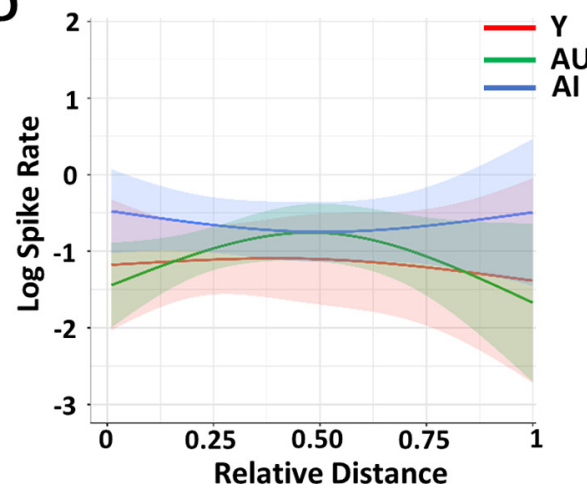

Figure 5. Nonspatial cells do not contribute to age-related hyperactivity. $\boldsymbol{A}$, Examples of well-isolated pyramidal neuron clusters from two different Al rats showing a lack of location-specific firing on the circular track. $\boldsymbol{B}$, Active cells were categorized as spatial cells, low rate cells, or nonspatial cells. There were significant group differences in the proportions of cell types in each subregion $\left(\chi^{2}, p<0.05\right)$. The proportion of active cells with spatial fields is lower in Al rats compared with $\mathrm{AU}$ and $\mathrm{Y}$ rats. Correspondingly, the proportion of nonspatial cells in Al rats was higher compared with AU and $\mathrm{Y}$ rats across the subregions. C, Mean firing rates of nonspatial cells showed significant group $\times$ region interaction effects, but post hoc Tukey's tests showed that the only difference was in the distal region where AU rats had lower rates compared with $Y$ and Al rats $(* p<0.05)$. $D$, A linear mixed effects model that incorporates momentary speed as a fixed effect was used to analyze the mean firing rates along the CA3 transverse axis. The solid lines show the model's best fits, with $95 \%$ Cls. The mean firing rates along the transverse axis were not significantly different among the groups.

whether the aged rats had statistically significantly lower firing rates than Y rats from tetrodes located $70-100 \%$ along the transverse axis, but there was no statistically significant effect (95\% CI: $-5,41 \%$; $p=0.14$ ). We also performed a post hoc test on the data points $80-$ $100 \%$ along the transverse axis, on the justification that prior work (Lu et al., 2015) showed a sharp transition at $\sim 80 \%$ of the transverse axis in rate differences of cells in a global remapping experiment. From these data points, we estimated that $\mathrm{Y}$ rats had a firing rate that was $31 \%$ higher than the aged rats (95\% CI: $4,64 \%$; $p=0.02$ ). Thus, although it is clear that proximal CA3 cells are hyperactive in aged rats and this hyperactivity diminishes in the more distal part of $\mathrm{CA} 3$, the results are suggestive, albeit somewhat ambiguous, as to whether the trend fully reverses to hypoactivity in distal CA3.

Individual aged rats showed trends of more heterogeneous speed-firing rate relationships than Y rats (Fig. 4C). Consistent with prior reports (McNaughton et al., 1983; Wiener et al., 1989; Czurkó et al., 1999; Hirase et al., 1999; Ekstrom et al., 2001; Maurer et al., 2005), all four $Y$ rats showed increasing firing rates with increasing running speeds. However, the aged rats (especially AU rats) showed more heterogeneity in this pattern, as some aged rats showed the expected positive slopes whereas other rats showed negative or flat slopes.

Fewer place cells are active in aged than young CA3

A large number of well-isolated, highly active pyramidal cells did not show localized firing locations on the circular track in aged rats (Fig. 5A). These active cells tended to fire either all over the circular track or during head-scanning behaviors, when the animals were looking out to the distal cues in the room (Monaco et al., 2014). To compare the proportions of nonspatial cells across the age groups, active cells were categorized into three groups: place cells (that meet spatial criteria: $>0.75$ spatial information score with significance $p<0.01$ ); low rate cells (that meet spatial criteria but fired $<50$ spikes when the rat's head was on the track, i.e., excluding offtrack spikes); and active, nonspatial cells (that do not meet the spatial criteria). There were significant group differences in the proportions of cell types in each subregion (proximal: $\chi^{2}=10.87, p=0.03$; intermediate: $\chi^{2}=48.4, p<0.0001$; distal: $\chi^{2}=$ 9.53, $p=0.049$; Fig. $5 B$ ). AI rats had a lower proportion of place cells and a higher proportion of nonspatial cells in all the subregions compared with Y rats.

The previous analyses were limited to cells that were classified as place cells, in accordance with prior literature on hyperactivity of CA3 place cells in hippocampus (Wilson et al., 2005; Robitsek et al., 2015). Because there was a higher proportion of active, nonspatial cells in AI rats than the other groups, we examined whether the nonspatial cells contribute to the agerelated hyperactivity or hypoactivity. The average firing rates of the active, nonspatial cells across the age groups were not significantly different, except in the distal region where $\mathrm{AU}$ rats had lower rates compared with $\mathrm{Y}$ and AI rats (two-way ANOVA: group: $F_{(2,279)}=0.82, p=0.44$; region: $F_{(2,279)}=3.44$, $p=0.03$; and interaction: $F_{(4,279)}=2.83 p=0.03$; Tukey's post hoc tests, $p<0.05$; Fig. $5 C$ ). The linear mixed effects model that incorporates momentary speed as a fixed effect on the active, nonspatial cells (as in Fig. 4B) showed no significant effects. Thus, these results suggest that although there are more active nonspatial cells in AI rats than the other groups, these cells do not contribute substantially to the age-related differences in CA3 firing rates; rather, only the place cells contribute to the agerelated firing rate differences.

\section{Discussion}

The current study compared the firing properties of CA3 place cells from $\mathrm{Y}$ and aged rats. CA3 place cells in AU and AI rats were hyperactive in proximal CA3, which is consistent with the prior studies showing age-related hyperactivity in CA3 (Wilson et al., 2005; Robitsek et al., 2015; Haberman et al., 2017a; Maurer et al., 2017). However, our results showed that cells in distal CA3 of AU and AI rats were possibly hypoactive, or were not different, compared with Y rats. These results may seem to contradict the findings of Maurer et al. (2017), who showed that agedpoor performing rats had significantly higher numbers of cells expressing the immediate early gene Arc in CA3, but with no significant differences between proximal and distal CA3 subregions. 
However, the location of distal CA3 analyzed by Maurer et al. (2017) was not at the extreme distal end of CA3 but was located more toward the border of distal/intermediate CA3. Furthermore, the two studies measured related, but fundamentally different, quantities. Although Arc studies are useful indicators of the numbers of cells that are active under certain conditions (Guzowski et al., 1999), they are not accurate indicators of neural firing rates per se. Thus, there are no clear contradictions between the two studies. Instead, contrary to notions that there is an overall hyperactivity in aging CA3, our results demonstrate that age-related firing rate changes may be heterogeneous along the CA3 transverse axis, providing new insights to understanding the role of CA3 in age-related cognitive impairment.

\section{Role of aging CA3 in pattern separation and pattern completion}

Classic computational models propose that the hippocampus performs two processes that maximize memory storage and minimize interference in a distributed network: pattern separation, the ability to orthogonalize similar input patterns, and pattern completion, the ability to retrieve complete output patterns from partial or degraded input patterns. The DG has been proposed to perform pattern separation (Marr, 1969; McNaughton and Nadel, 1990; Rolls and Treves, 1998; Yassa and Stark, 2011), while CA3, because of its recurrent collaterals, has been proposed to perform pattern completion (Marr, 1971; McNaughton and Morris, 1987; McClelland and Goddard, 1996; Rolls and Treves, 1998). However, anatomic and functional gradients exist along the CA3 transverse axis (Ishizuka et al., 1990; Li et al., 1994; Witter, 2007; Hunsaker et al., 2008; Nakamura et al., 2013; Marrone et al., 2014; Lee et al., 2015; Lu et al., 2015; Sun et al., 2017); proximal CA3 is biased toward pattern separation and distal CA3 is biased toward pattern completion (Lee et al., 2015; Lu et al., 2015).

Prior work suggested that the hippocampal system trade-off between pattern separation and pattern completion might favor pattern completion in aged rats as the result of the hyperactivity in the pattern completion networks of CA3. This explanation fit with experimental data showing that aged rats were less likely than $\mathrm{Y}$ rats to form new representations when environments were altered (Tanila et al., 1997a,b; Wilson et al., 2004, 2005; Robitsek et al., 2015). Similarly, aged humans had deficits in remembering whether an image of an object was a previously seen image (a target) or one that was slightly altered (a lure; Bakker et al., 2012, 2015; Reagh et al., 2018). The authors interpreted these studies as a deficit in pattern separation, as the hyperactive CA3 networks tipped the balance in favor of pattern completion and prevented the memory networks from forming orthogonalized representations of the target and lure. Treatment with the antiepileptic drug, levetiracetam, rescued the memory deficit, suggesting that tamping down the CA3 hyperactivity restored the balance between pattern separation and pattern completion (Bakker et al., 2012, 2015; Robitsek et al., 2015). Further work implicated hypoactivity in the LEC and the DG (Geinisman et al., 1992; Small et al., 2004; Burke and Barnes, 2006; Reagh et al., 2018). Because the LEC is especially disrupted in aging compared with the MEC (Stranahan et al., 2011a,b; Reagh et al., 2018; Tran et al., 2019), the hypoactivity in LEC and DG fit well with the notion that a major factor in age-related memory impairment is an imbalance between pattern separation and pattern completion.

However, the part of CA3 that appears to underlie pattern completion (distal CA3) does not show hyperactivity in aged rats in the present study, and may even show hypoactivity. Instead, the part of CA3 that shows hyperactivity is the region that, along with the DG, is involved in pattern separation (Lee et al., 2015, 2020; Lu et al., 2015; GoodSmith et al., 2019). Thus, using the logic of Wilson et al. (2006), a simple model might suggest that aged subjects should show greater pattern separation because of the hyperactivity specific to proximal CA3. To resolve this apparent paradox, we propose a revised model, based on the parallel processing streams throughout the hippocampal transverse axis (Lee et al., 2020), that presents a more nuanced view of how the patterns of hyperactivity and potential hypoactivity along the transverse axis of aged rats may result in an imbalance of the pattern-completion/pattern-separation balance.

CA3 receives three major inputs (Fig. 6A): (1) perforant path inputs from the entorhinal cortex (Witter, 1993); (2) mossy fiber inputs from the DG (Blackstad et al., 1970; Swanson et al., 1978); and (3) recurrent collaterals from CA3 (Amaral and Lavenex, 2007). Entorhinal inputs increase, and mossy fiber inputs decrease, along the transverse axis from proximal to distal (Claiborne et al., 1986; Ishizuka et al., 1990; Witter, 2007; Sun et al., 2017). In humans, aged entorhinal cortex is associated with neurofibrillary tangles (Braak and Braak, 1995) and loss of cells in layer II by the time of a clinical diagnosis of $\mathrm{AD}$ (Gómez-Isla et al., 1996; Gallagher and Koh, 2011). In the absence of Alzheimer's pathology, aged entorhinal cortex is also associated with loss of synaptic markers, such as reelin, in rats (Stranahan et al., 2011a,b) and with hypoactivity in humans (Reagh et al., 2018). With reduced entorhinal function, the DG in aged rats receives fewer synaptic contacts from the entorhinal cortex than in Y rats (Geinisman et al., 1992; Burke and Barnes, 2006), which may correspond with decreased activity in aged DG (Small et al., 2004). In contrast, disruptions of inhibitory circuits in the aged DG (Andrews-Zwilling et al., 2010, 2012; Spiegel et al., 2013; Tran et al., 2019) have the potential to increase the output of DG neurons, perhaps disrupting pattern separation by decreasing the sparsity of the DG population. Thus, because proximal CA 3 in aged rats presumably receives a disrupted drive from pattern-separated outputs from DG, the recurrent collaterals in proximal CA3, facilitated by the hyperactivity in the aged rats (perhaps because of a reduction of feedforward inhibition from EC and feedback inhibition from decreased hilar interneurons with aging (Andrews-Zwilling et al., 2010, 2012; Spiegel et al., 2013), may override the DG inputs and create a larger basin of attraction that produces pattern completion (Fig. 6B,C) and a failure of aged rats to form new maps in altered environments (Tanila et al., 1997a,b; Wilson et al., 2004, 2005; Robitsek et al., 2015). However, Barnes et al. (1997) showed that in familiar environments, aged rats maintain multiple maps of the same spatial context, switching between maps across visits. Previous authors have discussed how these two sets of results can be reconciled (Rapp, 1998; Redish et al., 1998; Tanila, 1998). Here, we propose that the presence of multiple maps in aged rats in the Barnes et al. (1997) study may be because of multiple, weaker attractor states (Redish et al., 1998) specifically in distal CA3, related to the possible hypoactivity in the most distal part of CA3 (Rolls, 2019; Fig. 6C).

Although pattern completion and pattern separation are often presented as competing processes that produce a single output, we have argued previously that the gradients along the CA3 transverse axis might allow the system to output simultaneously a pattern-separated output and a pattern-completed output (Lee et al., 2020). Distal CA1 is associated with the LEC and proximal 
A

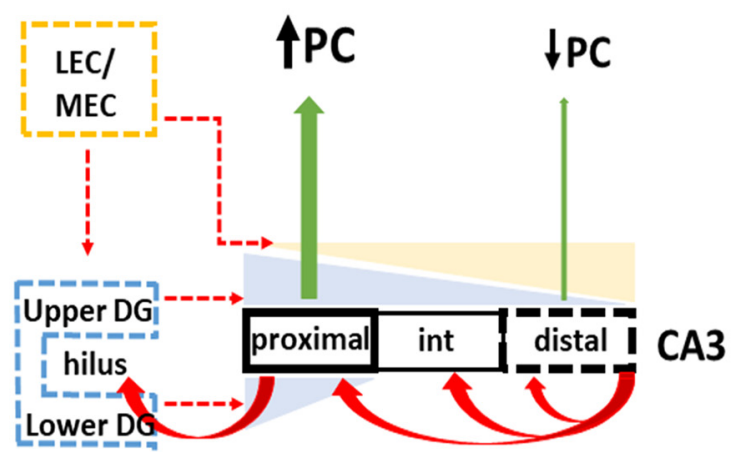

B Representational Similarity Young Representational Similarity
EC

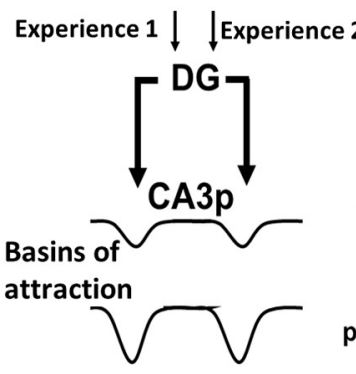

C

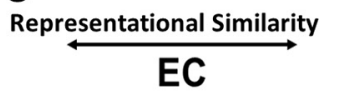

Experience 1 $\mid$ Experience 2

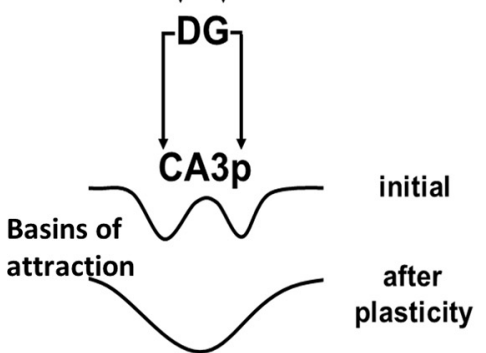

EC

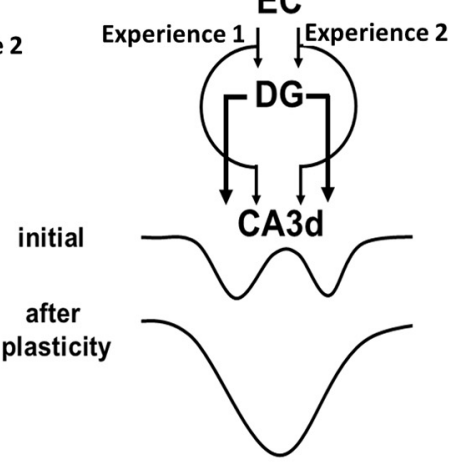

Aged Representational Similarity EC Experience 1 Experience 2

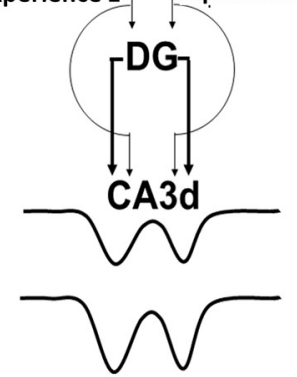

Figure 6. Hypothesized model of how changes in CA3 activity rates along the transverse axis affect the attractor dynamics of $C A 3$ and the transmission of pattern-separated outputs from DG. $A$, Three major inputs to CA3 are EC (with stronger inputs to distal CA3), DG (with stronger inputs to proximal $(A 3)$, and recurrent collaterals. Broken lines denote age-related reduction in function. In aging, with reduced EC and DG inputs, hyperactivity in proximal CA3 results in increased pattern completion $(\mathrm{PC})$ while potential hypoactivity in distal $C A 3$ results in weakened $P C$. $B$, For $Y$ rats, the standard model of $D G$ is that the $E C$ neural representations of two similar experiences will be similar (shown as distance between two input arrows along a "representational similarity" axis). The DG takes the two similar EC patterns and performs a pattern separation function, increasing the distance between the representations of the two experiences (i.e., the distance between the arrows representing the DG output to CA3 is larger than the distance between the two EC inputs). In proximal CA3 (CA3p), the strong input from the DG (both upper and lower blades), coupled with the lack of strong, direct EC inputs, imposes the separated patterns on CA3 attractor networks. Through learning, the recurrent collaterals of CA3 increase the strength of the attractor basins. In distal CA3 (CA3d), the DG inputs are somewhat weaker and the direct EC inputs are stronger than CA3p. Thus, the combined DG and EC input may impose initial patterns on CA3d that are somewhat closer together and overlapping than those imposed in CA3p. The stronger recurrent collateral system of $C A 3 d$ may override the external drive from $D G / E C$ and merge the two attractor basins to form a broader and deeper energy well, resulting in pattern completion (or generalization) of the two input patterns. C, For aged rats, disruptions in the DG
CA1 is associated with the MEC. Thus, memory deficits in aging may arise from a weakening of pattern separation (localized in the circuit from proximal CA3 through distal CA1 to deep LEC) as well as a weakening of attractor dynamics (localized in the circuit from distal CA3 through proximal CA1 to deep MEC). Of particular importance for humans, proximal CA3 appears to be disproportionately large compared with intermediate and distal CA3, as $\sim 75 \%$ of CA3 appears to be homologous to rodent proximal CA3 (Lim et al., 1997). This disproportionate increase in proximal CA3 may explain why human fMRI studies have shown evidence for hyperactivity and stronger pattern completion in older adults' DG/CA3 (Yassa et al., 2010, 2011; Reagh et al., 2018). The relative size of proximal CA 3 in humans suggests that the evolution of human episodic memory required an expansion of the pattern-separating function of the DG-proximal CA3-distal CA1-deep LEC pathway. Perhaps not surprising, these are the components of the hippocampal system that are affected earlier and more profoundly in aging.

A similar amount of hyperactivity in CA3 was observed in both AI and AU rats in the present study, which suggests a complex relationship among age-related hyperactivity, the balance between pattern separation and pattern completion in CA3, and performance in the water maze. Prior studies have shown that place cells in CA1 and CA3 showed rigidity (i.e., a lack of pattern separation between familiar and novel environments) and hyperactivity in AI rats (Wilson et al., 2004, 2005), thus establishing a correlational link among these three entities. One possibility is that $\mathrm{AU}$ rats employ compensatory mechanisms, unavailable to AI rats, that protect the computational integrity of hippocampal networks in the face of CA3 hyperactivity. For example, postsynaptic inhibition is enhanced in granule cells and CAl cells in AU rats compared with AI rats (Tran et al., 2018, 2019) and gene markers of synaptic inhibition across hippocampal subregions are increased in AU rats (Branch et al., 2019). Interactions among these cellular properties may affect neural population representations in ways that promote cognitive performance in AU rats. Alternatively, Johnson et al. (2017) showed that aged, Fisher 344-Brown Norway hybrid rats with intact water maze performance showed impairment in a mnemonic discrimination task of perceptually similar objects, suggesting that pattern separation ability may not be strongly related to water maze performance. However, the aged rats in that study did not show impairment in water maze performance, making the lack of correlation between water maze performance and pattern separation in aged animals somewhat inconclusive. To address these ambiguities, studies are in progress to directly examine the relationships between CA3 hyperactivity and neural representations that are

$\leftarrow$

circuitry, because of dysfunction of the EC inputs (especially LEC) and the local inhibitory circuitry of the DG hilus, are hypothesized to reduce the ability of the DG to separate the similar $\mathrm{EC}$ input patterns (i.e., the distance between the DG inputs to $C A 3$ is not as large as in $\mathrm{Y}$ animals, and the coordinated drive to CA3 may be reduced). The hyperactivity of CA3p cells may increase the relative strength of the CA3p attractor dynamics, overriding the DG inputs and causing a single basin of attraction (similar to that of CA3d in $\mathrm{Y}$ animals, but weaker because of the lower density of recurrent collaterals in CA3p). Thus, CA3p, which normally transmits a pattern-separated signal to distal CA1 in $\mathrm{Y}$ rats, instead transmits a pattern completed signal in aged rats, as seen in some studies (Tanila et al., 1997a,b). The possible hypoactivity of CA3d cells may result in weaker attractor basins in CA3d compared with $Y$ rats, preventing the merging of the attractor basins that occurs in $Y$ rats and in CA3p of aged rats. Thus, two stable attractor states, with relatively lower energy barriers between them, may result in the bistable representations seen in other studies (Barnes et al., 1997). 
thought to underlie pattern separation abilities in $\mathrm{AI}$ and $\mathrm{AU}$ rats (Lee et al., 2018).

\section{References}

Ahmed OJ, Mehta MR (2009) The hippocampal rate code: anatomy, physiology and theory. Trends Neurosci 32:329-338.

Aitchison J, Silvey SD (1960) Maximum-likelihood estimation procedures and associated tests of significance. J R Stat Soc Series B Stat Methodol 22:154-171.

Alme CB, Miao C, Jezek K, Treves A, Moser EI, Moser M-B (2014) Place cells in the hippocampus: eleven maps for eleven rooms. Proc Natl Acad Sci USA 111:18428-18435.

Amaral D, Lavenex P (2007) Hippocampal neuroanatomy. In: The hippocampus book. Oxford: Oxford University Press.

Amaral DG, Witter MP (1989) The three-dimensional organization of the hippocampal formation: a review of anatomical data. Neuroscience 31:571-591.

Andrews-Zwilling Y, Bien-Ly N, Xu Q, Li G, Bernardo A, Yoon SY, Zwilling D, Yan TX, Chen L, Huang Y (2010) Apolipoprotein E4 causes age- and Tau-dependent impairment of GABAergic interneurons, leading to learning and memory deficits in mice. J Neurosci 30:13707-13717.

Andrews-Zwilling Y, Gillespie AK, Kravitz AV, Nelson AB, Devidze N, Lo I, Yoon SY, Bien-Ly N, Ring K, Zwilling D, Potter GB, Rubenstein JLR, Kreitzer AC, Huang Y (2012) Hilar GABAergic interneuron activity controls spatial learning and memory retrieval. PLoS One 7:e40555.

Bakker A, Krauss GL, Albert MS, Speck CL, Jones LR, Stark CE, Yassa MA, Bassett SS, Shelton AL, Gallagher M (2012) Reduction of hippocampal hyperactivity improves cognition in amnestic mild cognitive impairment. Neuron 74:467-474.

Bakker A, Albert MS, Krauss G, Speck CL, Gallagher M (2015) Response of the medial temporal lobe network in amnestic mild cognitive impairment to therapeutic intervention assessed by fMRI and memory task performance. Neuroimage Clin 7:688-698.

Barnes CA, McNaughton BL, O'Keefe J (1983) Loss of place specificity in hippocampal complex spike cells of senescent rat. Neurobiol Aging 4:113-119.

Barnes CA, Suster MS, Shen J, McNaughton BL (1997) Multistability of cognitive maps in the hippocampus of old rats. Nature 388:272-275.

Berron D, Cardenas-Blanco A, Bittner D, Metzger CD, Spottke A, Heneka MT, Fliessbach K, Schneider A, Teipel SJ, Wagner M, Speck O, Jessen F, Düzel E (2019) Higher CSF tau levels are related to hippocampal hyperactivity and object mnemonic discrimination in older adults. J Neurosci 39:8788-8797.

Blackstad TW, Brink K, Hem J, Jeune B (1970) Distribution of hippocampal mossy fibers in the rat. An experimental study with silver impregnation methods. J Comp Neurol 138:433-449.

Braak H, Braak E (1995) Staging of Alzheimer's disease-related neurofibrillary changes. Neurobiol Aging 16:271-278; discussion 278-284.

Branch A, Monasterio A, Blair G, Knierim JJ, Gallagher M, Haberman RP (2019) Aged rats with preserved memory dynamically recruit hippocampal inhibition in a local/global cue mismatch environment. Neurobiol Aging 76:151-161.

Burke SN, Barnes CA (2006) Neural plasticity in the ageing brain. Nat Rev Neurosci 7:30-40

Claiborne BJ, Amaral DG, Cowan WM (1986) A light and electron microscopic analysis of the mossy fibers of the rat dentate gyrus. J Comp Neurol 246:435-458.

Csicsvari J, Hirase H, Czurko A, Buzsáki G (1998) Reliability and state dependence of pyramidal cell-interneuron synapses in the hippocampus: an ensemble approach in the behaving rat. Neuron 21:179-189.

Csicsvari J, Hirase H, Czurkó A, Mamiya A, Buzsáki G (1999) Oscillatory coupling of hippocampal pyramidal cells and interneurons in the behaving rat. J Neurosci 19:274-287.

Czurkó A, Hirase H, Csicsvari J, Buzsáki G (1999) Sustained activation of hippocampal pyramidal cells by "space clamping" in a running wheel. Eur J Neurosci 11:344-352.

Ekstrom AD, Meltzer J, McNaughton BL, Barnes CA (2001) NMDA receptor antagonism blocks experience-dependent expansion of hippocampal place fields. Neuron 31:631-638.
Fox SE, Ranck JB (1975) Localization and anatomical identification of theta and complex spike cells in dorsal hippocampal formation of rats. Exp Neurol 49:299-313.

Fox SE, Ranck JB (1981) Electrophysiological characteristics of hippocampal complex-spike cells and theta cells. Exp Brain Res 41:399-410.

Gallagher M, Koh MT (2011) Episodic memory on the path to Alzheimer's disease. Curr Opin Neurobiol 21:929-934.

Gallagher M, Burwell R, Burchinal M (1993) Severity of spatial learning impairment in aging: development of a learning index for performance in the Morris water maze. Behav Neurosci 107:618-626.

Geinisman Y, deToledo-Morrell L, Morrell F, Persina IS, Rossi M (1992) Age-related loss of axospinous synapses formed by two afferent systems in the rat dentate gyrus as revealed by the unbiased stereological dissector technique. Hippocampus 2:437-444.

Gómez-Isla T, Price JL, McKeel DW, Morris JC, Growdon JH, Hyman BT (1996) Profound loss of layer II entorhinal cortex neurons occurs in very mild Alzheimer's disease. J Neurosci 16:4491-4500.

GoodSmith D, Lee H, Neunuebel JP, Song H, Knierim JJ (2019) Dentate gyrus mossy cells share a role in pattern separation with dentate granule cells and proximal CA3 pyramidal cells. J Neurosci 39:9570-9584.

Gray DT, Barnes CA (2019) Experiments in macaque monkeys provide critical insights into age-associated changes in cognitive and sensory function. Proc Natl Acad Sci USA 116:26247-26254.

Guzowski JF, McNaughton BL, Barnes CA, Worley PF (1999) Environmentspecific expression of the immediate-early gene Arc in hippocampal neuronal ensembles. Nat Neurosci 2:1120-1124.

Haberman RP, Branch A, Gallagher M (2017a) Targeting neural hyperactivity as a treatment to stem progression of late-onset Alzheimer's disease. Neurotherapeutics 14:662-676.

Haberman RP, Koh MT, Gallagher M (2017b) Heightened cortical excitability in aged rodents with memory impairment. Neurobiol Aging 54:144151.

Hastie T, Tibshirani R, Friedman J (2009) The elements of statistical learning: data mining, inference, and prediction, Ed 2. San Diego: Springer.

Hirase H, Czurkó A, Csicsvari J, Buzsáki G (1999) Firing rate and theta-phase coding by hippocampal pyramidal neurons during space clamping. Eur J Neurosci 11:4373-4380.

Hunsaker MR, Rosenberg JS, Kesner RP (2008) The role of the dentate gyrus, $\mathrm{CA} 3 \mathrm{a}, \mathrm{b}$, and $\mathrm{CA} 3 \mathrm{c}$ for detecting spatial and environmental novelty. Hippocampus 18:1064-1073.

Ishizuka N, Weber J, Amaral DG (1990) Organization of intrahippocampal projections originating from CA3 pyramidal cells in the rat. J Comp Neurol 295:580-623.

Ishizuka N, Cowan WM, Amaral DG (1995) A quantitative analysis of the dendritic organization of pyramidal cells in the rat hippocampus. J Comp Neurol 362:17-45.

Johnson SA, Turner SM, Santacroce LA, Carty KN, Shafiq L, Bizon JL, Maurer AP, Burke SN (2017) Rodent age-related impairments in discriminating perceptually similar objects parallel those observed in humans. Hippocampus 27:759-776.

Knierim JJ (2002) Dynamic interactions between local surface cues, distal landmarks, and intrinsic circuitry in hippocampal place cells. J Neurosci 22:6254-6264.

Koh MT, Haberman RP, Foti S, McCown TJ, Gallagher M (2010) Treatment strategies targeting excess hippocampal activity benefit aged rats with cognitive impairment. Neuropsychopharmacology 35:1016-1025.

Laird NM, Ware JH (1982) Random-effects models for longitudinal data. Biometrics 38:963-974.

Lee H, Wang C, Deshmukh SS, Knierim JJ (2015) Neural population evidence of functional heterogeneity along the CA3 transverse axis: pattern completion versus pattern separation. Neuron 87:1093-1105.

Lee H, Tillekeratne A, Rao G, Lukish N, Gallagher M, Knierim JJ (2018) Local-global reference frame control in the CA3 region of the aged rats. Program No. 330.04. 2018 Neuroscience Meeting Planner. San Diego: Society for Neuroscience.

Lee H, GoodSmith D, Knierim JJ (2020) Parallel processing streams in the hippocampus. Curr Opin Neurobiol 64:127-134.

Li XG, Somogyi P, Ylinen A, Buzsáki G (1994) The hippocampal CA3 network: an in vivo intracellular labeling study. J Comp Neurol 339:181208. 
Lim C, Blume HW, Madsen JR, Saper CB (1997) Connections of the hippocampal formation in humans: I. The mossy fiber pathway. J Comp Neurol 385:325-351.

Lu L, Igarashi KM, Witter MP, Moser EI, Moser M-B (2015) Topography of place maps along the CA3-to-CA2 axis of the hippocampus. Neuron 87:1078-1092.

Marr D (1969) A theory of cerebellar cortex. J Physiol 202:437-470.

Marr D (1971) Simple memory: a theory for archicortex. Philos Trans R Soc Lond B Biol Sci 262:23-81.

Marrone DF, Satvat E, Odintsova IV, Gheidi A (2014) Dissociation of spatial representations within hippocampal region CA3. Hippocampus 24:14171420.

Maurer AP, Vanrhoads SR, Sutherland GR, Lipa P, McNaughton BL (2005) Self-motion and the origin of differential spatial scaling along the septotemporal axis of the hippocampus. Hippocampus 15:841-852.

Maurer AP, Johnson SA, Hernandez AR, Reasor J, Cossio DM, Fertal KE, Mizell JM, Lubke KN, Clark BJ, Burke SN (2017) Age-related changes in lateral entorhinal and CA3 neuron allocation predict poor performance on object discrimination. Front Syst Neurosci 11:49.

McClelland JL, Goddard NH (1996) Considerations arising from a complementary learning systems perspective on hippocampus and neocortex. Hippocampus 6:654-665.

McNaughton BL, Morris RGM (1987) Hippocampal synaptic enhancement and information storage within a distributed memory system. Trends Neurosci 10:408-415.

McNaughton BL, Nadel L (1990) Hebb-Marr networks and the neurobiological representation of action in space. In: Neuroscience and connectionist theory, developments in connectionist theory, pp 1-63. Hillsdale: Lawrence Erlbaum Associates, Inc.

McNaughton BL, Barnes CA, O'Keefe J (1983) The contributions of position, direction, and velocity to single unit activity in the hippocampus of freely-moving rats. Exp Brain Res 52:41-49.

Monaco JD, Rao G, Roth ED, Knierim JJ (2014) Attentive scanning behavior drives one-trial potentiation of hippocampal place fields. Nat Neurosci 17:725-731.

Nakamura NH, Flasbeck V, Maingret N, Kitsukawa T, Sauvage MM (2013) Proximodistal segregation of nonspatial information in CA3: preferential recruitment of a proximal CA3-distal CA1 network in nonspatial recognition memory. J Neurosci 33:11506-11514.

O'Keefe J (1976) Place units in the hippocampus of the freely moving rat. Exp Neurol 51:78-109.

O'Keefe J, Dostrovsky J (1971) The hippocampus as a spatial map. Preliminary evidence from unit activity in the freely-moving rat. Brain Res 34:171-175.

R Core Team (2013) R: a language and environment for statistical computing, Vienna: R Foundation for Statistical Computing. Available at https://www.R-project.org/.

Rapp PR (1998) Representational organization in the aged hippocampus. Hippocampus 8:432-435.

Reagh ZM, Noche JA, Tustison NJ, Delisle D, Murray EA, Yassa MA (2018) Functional imbalance of anterolateral entorhinal cortex and hippocampal dentate/CA3 underlies age-related object pattern separation deficits. Neuron 97:1187-1198.e4.

Redish AD, McNaughton BL, Barnes CA (1998) Reconciling Barnes et al. (1997) and Tanila et al. (1997a,b). Hippocampus 8:438-443.

Robitsek J, Ratner MH, Stewart T, Eichenbaum H, Farb DH (2015) Combined administration of levetiracetam and valproic acid attenuates age-related hyperactivity of CA3 place cells, reduces place field area, and increases spatial information content in aged rat hippocampus. Hippocampus 25:1541-1555.

Rolls ET (2019) Attractor network dynamics, transmitters, and memory and cognitive changes in aging. In: Cognitive changes and the aging brain. Cambridge: Cambridge University Press.

Rolls ET, Treves A (1998) Neural networks and brain function. Oxford: Oxford University Press.

Samson RD, Barnes CA (2013) Impact of aging brain circuits on cognition. Eur J Neurosci 37:1903-1915.

Shen J, Barnes CA, McNaughton BL, Skaggs WE, Weaver KL (1997) The effect of aging on experience-dependent plasticity of hippocampal place cells. J Neurosci 17:6769-6782.
Skaggs WE, McNaughton BL, Wilson MA, Barnes CA (1996) Theta phase precession in hippocampal neuronal populations and the compression of temporal sequences. Hippocampus 6:149-172.

Small SA, Chawla MK, Buonocore M, Rapp PR, Barnes CA (2004) Imaging correlates of brain function in monkeys and rats isolates a hippocampal subregion differentially vulnerable to aging. Proc Natl Acad Sci USA 101:7181-7186.

Spiegel AM, Koh MT, Vogt NM, Rapp PR, Gallagher M (2013) Hilar interneuron vulnerability distinguishes aged rats with memory impairment. J Comp Neurol 521:3508-3523.

Stranahan AM, Haberman RP, Gallagher M (2011a) Cognitive decline is associated with reduced reelin expression in the entorhinal cortex of aged rats. Cereb Cortex 21:392-400.

Stranahan AM, Salas-Vega S, Jiam NT, Gallagher M (2011b) Interference with reelin signaling in the lateral entorhinal cortex impairs spatial memory. Neurobiol Learn Mem 96:150-155.

Sun Q, Sotayo A, Cazzulino AS, Snyder AM, Denny CA, Siegelbaum SA (2017) Proximodistal heterogeneity of hippocampal CA3 pyramidal neuron intrinsic properties, connectivity, and reactivation during memory recall. Neuron 95:656-672.e3.

Swanson LW, Wyss JM, Cowan WM (1978) An autoradiographic study of the organization of intrahippocampal association pathways in the rat. J Comp Neurol 181:681-715.

Tanila H (1998) Unique features in the processing of spatial information by the aged hippocampus as shown by place cell recording studies: a response to Peter Rapp's commentary "Representational organization in the aged hippocampus." Hippocampus 8:436-437.

Tanila H, Shapiro M, Gallagher M, Eichenbaum H (1997a) Brain aging: changes in the nature of information coding by the hippocampus. J Neurosci 17:5155-5166.

Tanila H, Sipilä P, Shapiro M, Eichenbaum H (1997b) Brain aging: impaired coding of novel environmental cues. J Neurosci 17:5167-5174.

Thomé A, Gray DT, Erickson CA, Lipa P, Barnes CA (2016) Memory impairment in aged primates is associated with region-specific network dysfunction. Mol Psychiatry 21:1257-1262.

Tran T, Gallagher M, Kirkwood A (2018) Enhanced postsynaptic inhibitory strength in hippocampal principal cells in high-performing aged rats. Neurobiol Aging 70:92-101.

Tran T, Bridi M, Koh MT, Gallagher M, Kirkwood A (2019) Reduced cognitive performance in aged rats correlates with increased excitation/inhibition ratio in the dentate gyrus in response to lateral entorhinal input. Neurobiol Aging 82:120-127.

Wiener SI, Paul CA, Eichenbaum H (1989) Spatial and behavioral correlates of hippocampal neuronal activity. J Neurosci 9:2737-2763.

Wilent WB, Nitz DA (2007) Discrete place fields of hippocampal formation interneurons. J Neurophysiol 97:4152-4161.

Wilson IA, Ikonen S, Gureviciene I, McMahan RW, Gallagher M, Eichenbaum H, Tanila H (2004) Cognitive aging and the hippocampus: how old rats represent new environments. J Neurosci 24:3870-3878.

Wilson IA, Ikonen S, Gallagher M, Eichenbaum H, Tanila H (2005) Ageassociated alterations of hippocampal place cells are subregion specific. J Neurosci 25:6877-6886.

Wilson IA, Gallagher M, Eichenbaum H, Tanila H (2006) Neurocognitive aging: prior memories hinder new hippocampal encoding. Trends Neurosci 29:662-670.

Witter MP (1993) Organization of the entorhinal-hippocampal system: a review of current anatomical data. Hippocampus 3:33-44.

Witter MP (2007) Intrinsic and extrinsic wiring of CA3: indications for connectional heterogeneity. Learn Mem 14:705-713.

Yassa MA, Stark CEL (2011) Pattern separation in the hippocampus. Trends Neurosci 34:515-525.

Yassa MA, Stark SM, Bakker A, Albert MS, Gallagher M, Stark CEL (2010) High-resolution structural and functional MRI of hippocampal CA3 and dentate gyrus in patients with amnestic mild cognitive impairment. Neuroimage 51:1242-1252.

Yassa MA, Mattfeld AT, Stark SM, Stark CEL (2011) Age-related memory deficits linked to circuit-specific disruptions in the hippocampus. Proc Natl Acad Sci USA 108:8873-8878. 